\title{
Nilai Ekonomi Objek Wisata Alam Pantai Lubang Buaya Di Negeri Morella Kabupaten Maluku Tengah
}

\section{(Economic Value of Natural Tourism Objects of Lubang Buaya Beach in Morella Village, Central Maluku Regency)}

\author{
Pratiwi Herlina W. ${ }^{*}$, Iskar ${ }^{2} \&$ Thomas M. Silaya ${ }^{2}$ \\ 1Mahasiswa Jurusan Kehutanan, Fakultas Pertanian, Universitas Pattimura Ambon, 97233 \\ 2Jurusan Kehutanan, Fakultas Pertanian, Universitas Pattimura Ambon, 97233
}

Email : wulan.pratiwi@gmail.com

\begin{abstract}
A natural tourism object is a form of tourism activity that utilizes the potential of natural resources and environmental management. The economic valuation of natural tourism needs to be done to see the value of the existence of nature tourism, which is sometimes valued. One method that can measure the economic value of a tourist area is the Travel Cost Method (TCM). Therefore this study aims to analyze the economic value of the natural tourism object of Lubang Buaya Beach in Negeri Morella, Central Maluku Regency. The results showed that the travel cost (Travel Cost) obtained 69,220 travel costs/person/visit, and the economic value of OWA Lubang Buaya Beach is Rp. 83,064,000 / year. OWA Lubang Buaya Beach in the perception of visitors is a safe place of recreation, beautiful natural beauty, and easy accessibility. It's just that the layout is not good, and tourism facilities are incomplete. So the need for additional facilities and better management. The results of the study of the attraction of beach attractions obtained only elements of beauty and comfort have all aspects of the assessment of the seven elements of the assessment criteria.
\end{abstract}

KEYWORDS: Nature tourism objects, economic value, banquet costs, Lubang Buaya beach

\section{INTISARI}

Objek wisata alam merupakan bentuk kegiatan wisata yang memanfaatkan potensi sumberdaya alam dan tata lingkungan. Valuasi nilai ekonomi wisata alam perlu dilakukan untuk melihat nilai dari keberadaan sebuah wisata alam yang terkadang dinilai under value. Salah satu metode yang dapat digunakan untuk mengukur nilai ekonomi suatu kawasan wisata adalah metode biaya perjalanan atau Travel Cost Method (TCM). Oleh karena itu penelitian ini bertujuan untuk menganalisis nilai ekonomi objek bisata alam Pantai Lubang Buaya di Negeri Morella Kabupaten Maluku Tengah. Hasil penelitian menunjukkan bahwa biaya perjalanan (Travel Cost) diperoleh biaya perjalanan 69.220/orang/kunjungan dan nilai ekonomi OWA Pantai Lubang Buaya adalah sebesar Rp. 83.064.000,-/tahun. OWA Pantai Lubang Buaya dalam persepsi pengunjung merupakan tempat rekreasi yang aman, memiliki keindahan alam yang indah, aksesibilitas mudah, hanya saja tata ruang kurang baik dan fasilitas wisata yang kurang lengkap. Sehingga perlu adanya penambahan fasilitas dan pengelolaan yang lebih baik lagi. Hasil penelitian daya tarik objek wisata pantai diperoleh hanya unsur keindahan dan kenyamanan memiliki semua aspek penilaian dari ketujuh unsur kriteria penilaian.

KATA KUNCI : Objek wisata alam, nilai ekonomi, biaya perjalanan, pantai Lubang Buaya 
Nilai Ekonomi Objek Wisata Alam Pantai Lubang Buaya Di Negeri Morella Kabupaten Maluku Tengah (Pratiwi Herlina W., Iskar \& Thomas M. Silaya)

\section{PENDAHULUAN}

Penilaian ekonomi suatu sumberdaya alam dan jasa lingkungan sangat diperlukan dalam pembangunan wilayah. Kegiatan wisata alam merupakan suatu kegiatan pemanfaatan sumberdaya alam yang tidak mengeksploitasi sumberdaya alam, tetapi hanya memanfaatkan keindahan alam. Penilaian ekonomi wisata perlu dilakukan untuk memberikan nilai yang sebenarnya terhadap lingkungan sebagai pemberi jasa. Dengan mengetahui besarnya nilai ekonomi wisata, maka ada dasar untuk memelihara lingkungan tersebut agar tetap lestari.

Nilai ekonomi jasa wisata merupakan salah satu bahan pertimbangan dalam pengembangan bentuk-bentuk layanan oleh manajemen obyek wisata. Nilai ekonomi secara khusus dapat diketahui dengan teknik pengukuran tidak langsung berupa travel cost method (TCM) atau metode biaya perjalanan. Tujuan dasar TCM adalah ingin mengetahui nilai kegunaan (use value) dari sumberdaya alam melalui pendekatan biaya yang dikeluarkan untuk mengkonsumsi jasa dari sumberdaya alam (Fauzi, 2006).

Prospek pariwisata yang memperlihatkan kecenderungan meningkat dari waktu ke waktu dan besarnya potensi wisata yang dimiliki Indonesia juga menjadi pemicu berkembangnya pariwisata di Indonesia. Salah satu potensi wisata yang dapat dijadikan sebagai penunjang pengembangan pariwisata adalah taman wisata alam. Berdasarkan Undang-Undang No. 5 Tahun 1990, taman wisata alam merupakan kawasan pelestarian alam yang pemanfaatan utamanya adalah untuk kegiatan pariwisata dan rekreasi alam. Padatnya aktivitas di kota besar, diikuti dengan kemacetan lalu lintas dan polusi udara menjadikan obyek wisata dengan konsep back to nature banyak diminati oleh masyarakat, khususnya masyarakat perkotaan untuk menghilangkan kepenatan selama beraktivitas. Wisata alam dapat memberikan sensasi relaksasi sehingga dapat membangkitkan kembali semangat mereka untuk menjalankan aktivitas sepulang berwisata.

Para wisatawan dalam melakukan kegiatan wisata pada umumnya rela meluangkan waktu dan mengeluarkan biaya yang cukup banyak, dan tidak memperdulikan jarak yang ditempuh untuk mengunjungi suatu obyek wisata. Hal ini dikarenakan kegiatan wisata yang dilakukan tersebut digunakan untuk mengisi waktu luang pada saat tidak bekerja, atau berkumpul dengan teman maupun keluarga, serta untuk menikmati keindahan panorama alam. Namun, tanpa disadari biaya yang dikeluarkan oleh wisatawan dalam melakukan kunjungan ke obyek wisata kurang diperhatikan dalam manfaat nilai ekonominya terhadap pengembangan kawasan wisata tersebut. Wisatawan dalam melakukan perjalanan wisata pada umumnya untuk menikmati keindahan dan panorama alam serta istirahat dan bersantai bersama keluarga. Oleh karena itu, mengetahui manfaat nilai ekonomi menggunakan peran pendekatan biaya perjalanan perlu di kaji pengaruhnya dalam 
pengembangan prasarana dan sarana pada Objek Wisata Alam Pantai Lubang Buaya dan juga sebagai informasi bagi pengunjung dalam perencanaan ke tempat wisata.

Negeri Morella adalah salah satu negeri adat yang masuk dalam wilayah Kecamatan Leihitu. Negeri ini kurang lebih berjarak $35 \mathrm{Km}$ dari Ibukota Provinsi Maluku. Potensi kebun masyarakat yang dimilki negeri ini antara lain Pala (Myristica fragrans), Cengkeh (Eugenia aromaticum), Coklat (Theobroma cacao), Kelapa (Cocos nucifera), Rotan (Calamus spp), dan Durian (Durio zibethinus). Selain potensi darat yang dimiliki, negeri ini juga memiliki beberapa Objek Wisata Alam (OWA) yang salah satu diantarannya adalah Pantai Lubang Buaya yang konon memiliki sejarah dan cerita mistik yang sampai saat ini masih diyakini oleh warga setempat. Selain potensi sosial budayanya ada juga potensi flora seperti Gayam (Inocarpus fagifera), Samama (Anthocepalus macrophylus), Kasuari (Casuarina equisetifolia), Ketapang (Terminalia catappa), Gufasa (Vitex cofassus), Pulai (Alstonia scholaris) dan potensi lautnya seperti Ikan Kakatua (Scarus scholaris), Ikan Kerapu (Epinephelinae), Ikan Hiu (Selachimorpha), Ikan Baronang (Siganus sp), Ikan Bubara (Caranx sp), Udang (Caridea), Tongkol (Euthynnus affinis), Tuna (Thunnus) serta terdapat terumbu karang yang masih alami dengan air laut berwarna hijau tosca. Bentuk OWA Pantai Lubang Buaya yang unik karena berbentuk seperti huruf U menjadikan tempat ini berbeda dari tempat wisata lainnya.

Pengembangan fasilitas terus dilakukan oleh pengelola OWA Pantai Lubang Buaya, pantai ini telah ada sejak lama namun baru terkenal akhir-akhir ini sebab adanya promosi dari wisatawan yang berkunjung dan mempublikasikannya melalui media sosial. Saat ini, pengelola berusaha untuk mengembangkan potensi yang ada dengan membangun jalan masuk ke lokasi pantai, memperbaiki dan menambah fasilitas umum dan membuat lahan parkir yang memadai. Hanya saja pengelolaan OWA Pantai Lubang Buaya belum masuk kedalam Rencana Induk Pariwisata. Sehingga yang mengelola OWA tersebut adalah keluarga yang memiliki lahan OWA Pantai Lubang Buaya.

Berdasarkan permasalahan di atas, penelitian ini bertujuan untuk menganalisis nilai ekonomi objek wisata alam Pantai Lubang Buaya di Negeri Morella Kabupaten Maluku Tengah.

\section{METODE PENELITIAN}

\section{Lokasi dan Waktu Penelitian}

Penelitian dilakukan di Objek Wisata Alam (OWA) Pantai Lubang Buaya Negeri Morella Kecamatan Leihitu Kabupaten Maluku Tengah pada bulan Juli sampai Agustus 2017 disajikan pada Gambar 1 dan Gambar 2. 
Nilai Ekonomi Objek Wisata Alam Pantai Lubang Buaya Di Negeri Morella Kabupaten Maluku Tengah (Pratiwi Herlina W., Iskar \& Thomas M. Silaya)

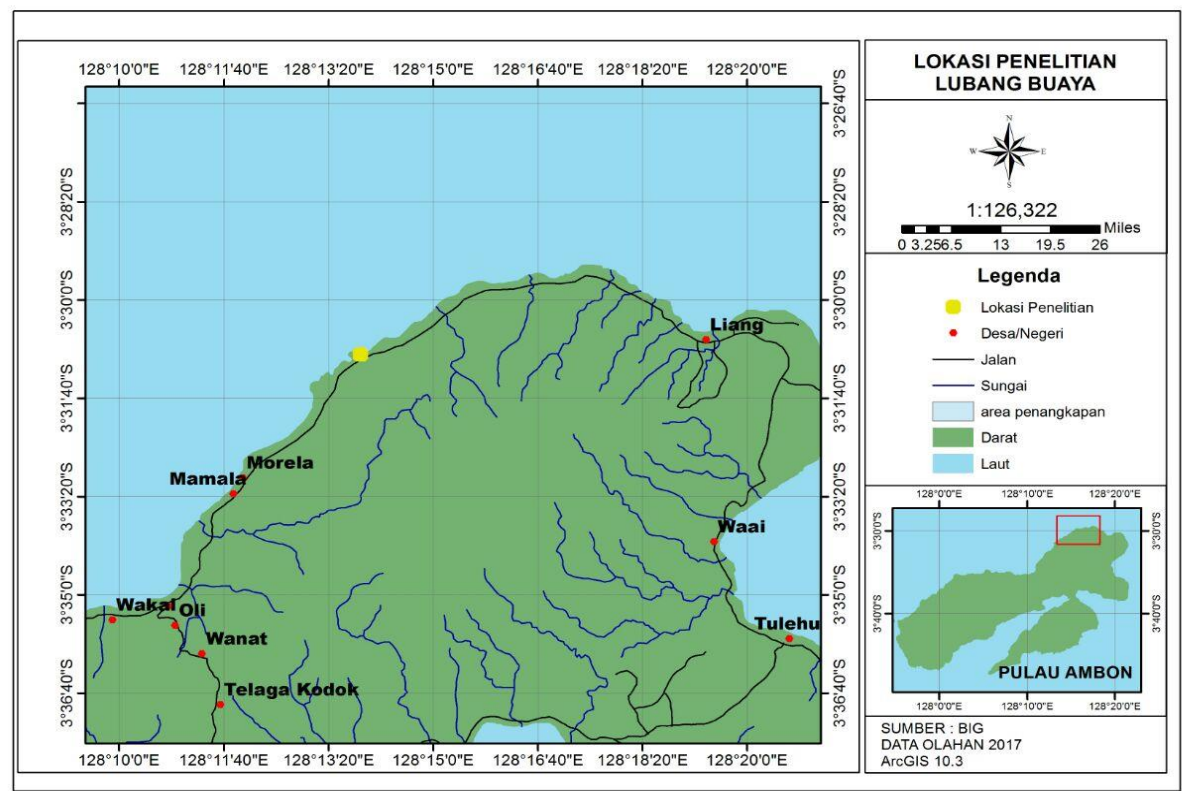

Gambar 1. Peta Lokasi OWA Pantai Lubang Buaya

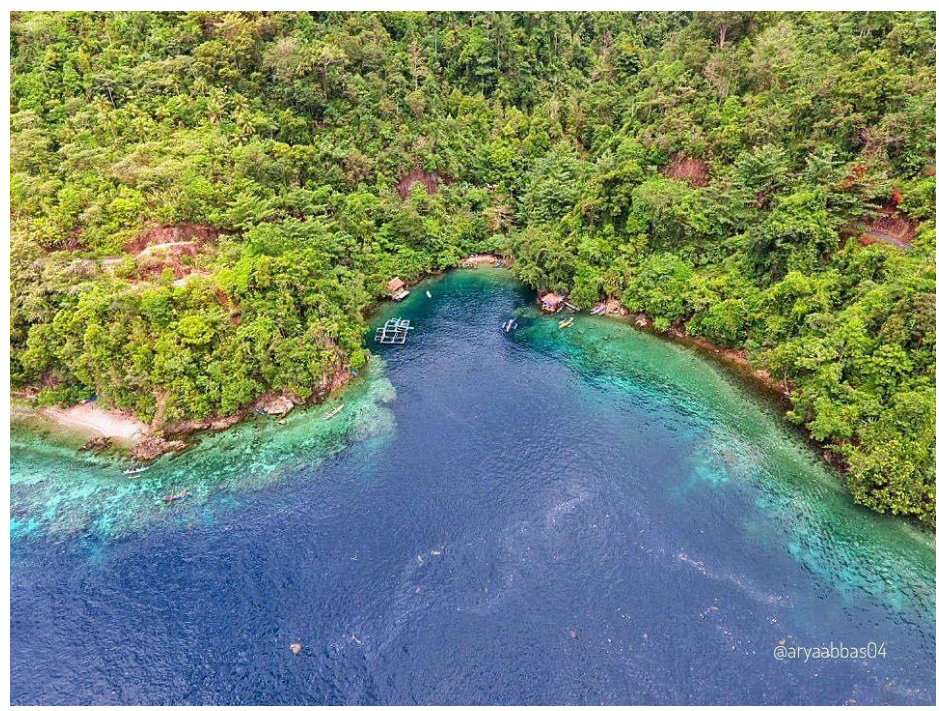

Gambar 2. Landscape OWA Pantai Lubang Buaya (Sumber: Arya Abbas, 2017).

\section{Metode Pengumpulan Data}

Data penelitian berupa data primer dan data sekunder, dan diperoleh melalui pengamatan dan wawancara langsung kepada pengunjung menggunakan kuisioner. Data primer yang diperoleh diantaranya:

1. Karakteristik pengunjung terdiri atas umur, jenis kelamin, tingkat pendidikan, pekerjaan, pendapatan, asal tempat tinggal, cara melakukan kunjungan, waktu tempuh dan alasan kedatangan. 
2. Penilaian pengunjung terhadap kawasan dan kualitas pelayanan seperti kemudahan mencapai lokasi, keindahan alam, keamanan, aksesibilitas, sistem tata ruang dan OWA Pantai Lubang Buaya.

3. Biaya Perjalanan dari pengunjung menuju lokasi objek wisata.

Data sekunder yang digunakan dalam penelitian ini diperoleh dari studi literatur berbagai buku, artikel, skripsi terdahulu yang relevan, instansi terkait seperti badan pusat statistik, Dinas Pariwisata dan Kebudayaan Kabupaten Maluku Tengah, dan sumber lainnya yang mendukung topik penelitian. Data sekunder yang dibutuhkan dalam penelitian antara lain gambaran umum lokasi wisata, serta informasi yang menunjang penelitian.

Pengambilan sample (responden) dilakukan secara non-acak (non-probability sampling) yaitu semua objek penelitian tidak mempunyai kesempatan yang sama untk dipilih sebagai responden (Juanda, 2007 dalam Susilowati, 2009). Pengambilan sampel untuk pengunjung dilakukan secara purposive atau judgement sampling, yaitu pengambilan responden yang ditemui di lokasi secara disengaja sesuai dengan persyaratan yang dikehendaki, yaitu sesuai dengan kriteria penelitian. Kriteria yang dimaksud adalah responden yang diwawancarai merupakan pengunjung Objek Wisata Alam Pantai Lubang Buaya dengan usia di atas 17 tahun yang dinilai dapat diajak berinteraksi sehingga mudah untuk mendapatkan data yang diperlukan dan dianggap sudah dapat menilai manfaat dari barang dan jasa lingkungan. Wawancara akan dilakukan melalui kuisioner kepada pengunjung dengan banyaknya responden 100 orang..

\section{Analisis Data}

Analisis data menggunakan Rumus Biaya Perjalanan (Travel Cost Method-TCM). Menurut Sulistiono (2007) yang etrdiri atas beberapa tahapan penentuan nilai ekonomi wisata alam yaitu :

1. Menentukan besarnya biaya perjalanan rata-rata dari jumlah total biaya perjalanan yang dikeluarkan selama melakukan perjalanan atau kegiatan rekreasi.

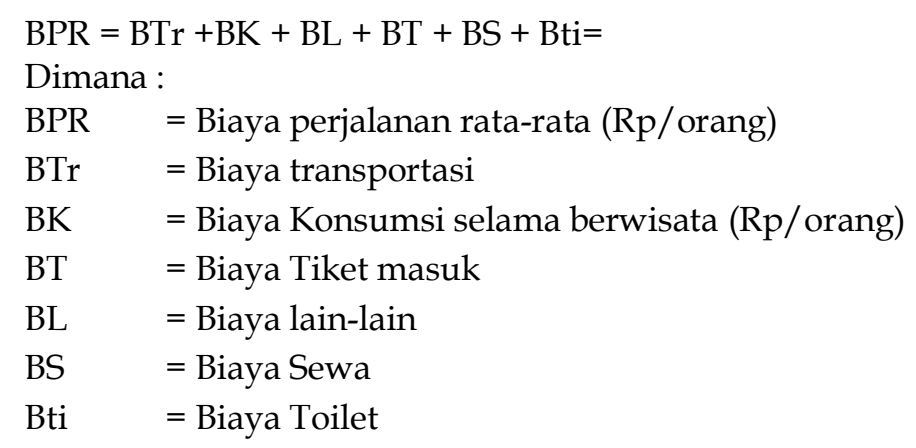



Nilai Ekonomi Objek Wisata Alam Pantai Lubang Buaya Di Negeri Morella Kabupaten Maluku Tengah (Pratiwi Herlina W., Iskar \& Thomas M. Silaya)

2. Menentukan nilai ekonomi wisata

Nilai ekonomi wisata didapatkan dari total kesediaan membayar seluruh tingkat harga karcis tanda masuk yang berlaku. Maka nilai ekonomi kawasan wisata alam dapat ditentukan dengan rumus :

$\mathrm{NE}=\sum$ Bpi $\times \mathrm{JP}$

Dimana :

$\mathrm{N} \quad=$ Nilai ekonomi kawasan wisata alam

$\sum$ Bpi $=$ Biaya perjalanan rata-rata

$\mathrm{JP} \quad=$ Jumlah pengunjung

\section{a. Analisis Kualitatif}

Analisis data dilakukan dengan pendekatan deskriptif kualitatif yang dikemukakan oleh Miles and Huberman dalam sugiyono (2014). Aktifitas dalam analisis data dilakukan secara interaktif dan berlangsung secara terus menerus pada setiap tahapan penelitian sampai datanya jenuh. Aktivitas dalam analisis data yaitu reduksi data, penyajian (display) data, verivikasi dan kesimpulan. Langkah - langkah dalam analisis data dapat dilihat pada

\section{Gambar 3.}

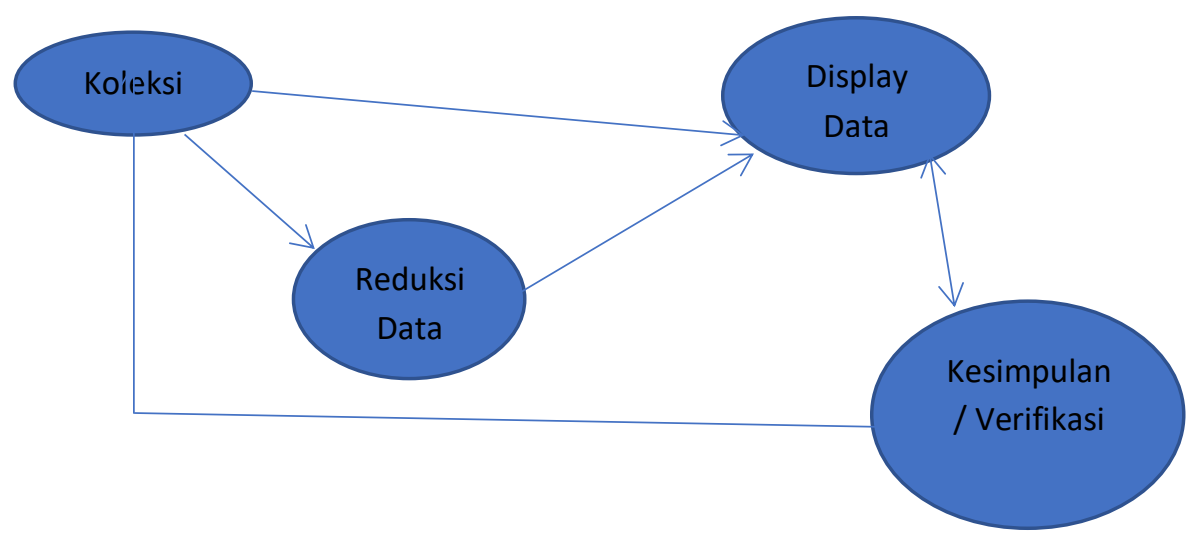

Gambar 3. Langkah-langkah dalam analisis data (Sumber : Miles dan Huberman, 1985 dalam Sugiyono, 2014)

b. Metode Skoring

Data mengenai potensi ODTW diolah dengan menggunakan Pedoman Analisis Daerah Operasi Objek dan Daya Tarik Wisata Alam (ADO-ODTWA) Direktorat Jenderal PHKA (2003). Jumlah nilai satu kriteria penilaian ODTWA dapat dihitung dengan persamaan sebagai berikut:

$\mathrm{S}=\mathrm{N} \times \mathrm{B}$

Keterangan :

$\mathrm{S} \quad=$ skor/nilai suatu kriteria

$\mathrm{N} \quad=$ jumlah nilai unsur-unsur pada kriteria

$\mathrm{B} \quad=$ bobot nilai 

Masing-masing kriteria tersebut dalam penilaiannya terdiri atas unsur dan sub unsur yang berkaitan. Nilai masing-masing unsur dipilih dari salah satu angka yang terdapat pada kriteria penilaian ODTWA sesuai dengan potensi dan kondisi masing-masing lokasi (Tabel 1).

Tabel 1. Pembagian Klasifikasi dan Skoring Penilaian ODTWA

\begin{tabular}{cccc}
\hline No & Variabel yang diukur & Skor & Klasifikasi \\
\hline 1 & & 3 & $234-300$ (Sangat Aman) \\
2 & Tingkat Keamanan & 2 & $167-234$ (Aman) \\
3 & & 1 & $100-167$ (Kurang Aman) \\
\hline 1 & \multirow{2}{*}{ Keindahan Alam } & 3 & $234-300$ (Sangat Indah) \\
2 & & 2 & $167-234$ (Indah) \\
3 & & 1 & $100-167$ (Kurang Indah) \\
\hline 1 & \multirow{2}{*}{ Aksesibilitas } & 3 & $234-300$ (Sangat Mudah) \\
2 & & 2 & $167-234$ (Mudah) \\
3 & & 1 & $100-167$ (Kurang Mudah) \\
\hline 1 & \multirow{3}{*}{ Sistem Tata Ruang } & 3 & $234-300$ (Sangat Baik) \\
3 & & 2 & $167-234$ (Baik) \\
\hline 1 & & 1 & $100-167$ (Kurang Baik) \\
2 & Fasilitas Wisata & 3 & $234-300$ (Sangat Lengkap) \\
3 & & 2 & $167-234$ (Lengkap) \\
\hline
\end{tabular}

\section{HASIL DAN PEMBAHASAN}

\section{Persepsi Pengunjung Mengenai Objek Wisata Alam Pantai Lubang Buaya}

Hasil wawancara dan kuisioner mengenai penilaian pengunjung terhadap OWA Lubang Buaya, meliputi keadaan keamanan objek wisata, keindahan alam objek wisata, kemudahan menjangkau lokasi (aksesibilitas), sistem tata ruang objek wisata, dan penyediaan fasilitas rekreasi.

a. Keamanan

Hasil perhitungan skoring keamanan diperoleh skor penilaian 189, yang berarti bahwa klasifikasi OWA Pantai Lubang Buaya termasuk tempat wisata yang aman untuk responden kunjungi. Hal ini senanda dengan penelitian Suwantoro (2002) mengatakan bahwa permintaan pariwisata tergantung pada fasilitas, pelayanan dan keamanan secara tidak langsung seperti sikap penduduk setempat kepada pengunjung sebagaimana disajikan pada Tabel 2.

Tabel 2. Rekapitulasi Pendapat Responden Mengenai Tingkat Keamanan

\begin{tabular}{lccc}
\hline Tingkat Keamanan & Skala Penilaian & Jumlah (Orang) & Jumlah Skor Penilaian \\
\hline Sangat Aman & 3 & 9 & 27 \\
Aman & 2 & 71 & 142 \\
Kurang Aman & 1 & 20 & 20 \\
\hline Total & & 100 & 189 \\
\hline
\end{tabular}

\section{b. Keindahan Alam}

Hasil perhitungan skoring mengenai keindahan alam diperoleh skor penilaian 228, ini berarti berdasarkan pengklasifikasian OWA Pantai Lubang Buaya memiliki keindahan alam 

Nilai Ekonomi Objek Wisata Alam Pantai Lubang Buaya Di Negeri Morella Kabupaten Maluku Tengah (Pratiwi Herlina W., Iskar \& Thomas M. Silaya)

yang indah. Pendapat tersebut sesuai dengan data yang diperoleh bahwa objek wisata ini memiliki nilai yang indah dimata responden. Keindahan alam ini sesuai dengan objek wisata yang memiliki keindahan panorama pantainya dan bentuk bebatuan yang unik serta pemandangan karang-karang yang masih terjaga kelestariannya.

Tabel 3. Rekapitulasi Pendapat Responden Mengenai Keindahan Alam

\begin{tabular}{lccc}
\hline Keindahan Alam & Skala Penilaian & Jumlah (Orang) & Jumlah Skor Penilaian \\
\hline Sangat Indah & 3 & 31 & 93 \\
Indah & 2 & 66 & 132 \\
Kurang Indah & 1 & 3 & 3 \\
\hline Total & & 100 & 228 \\
Sumber: Data Primer Diolah, 2017 & &
\end{tabular}

c. Aksesibilitas

Hasil perhitungan skoring mengenai aksesibilitas diperoleh skor penilaian 198, ini berarti berdasarkan pengklasifikasian OWA Pantai Lubang Buaya tergolong mudah dalam menjangkau Objek Wisatanya. Kondisi tersebut sesuai dengan pendapat responden yang tidak mengalami kesulitan berarti dalam mengunjungi tempat wisata. Aksesibilitas yang mudah menuju objek wisata dapat meningkatkan permintaan pengunjung terhadap kunjungan ke tempat wisata. Hal ini sesuai juga dengan pendapat Suwantoro (2002), yang menyatakan bahwa pembangunan prasarana wisata yang mempertimbangkan kondisi dan lokasi akan meningkatkan aksesibilitas suatu objek wisata yang pada giliranya akan meningkatkan daya tarik objek wisata itu sendiri.

Tabel 4. Rekapitulasi Pendapat Responden Mengenai Aksesibilitas

\begin{tabular}{lccc}
\hline \multicolumn{1}{c}{ Aksesibilitas } & Skala Penilaian & Jumlah (Orang) & Jumlah Skor Penilaian \\
\hline Sangat Mudah & 3 & 8 & 24 \\
Mudah & 2 & 82 & 164 \\
Sulit & 1 & 10 & 10 \\
\hline Total & 100 & 198 \\
\hline Sumber: Data Primer Diolah, 2017 & &
\end{tabular}

\section{c. Sistem Tata Ruang Objek Wisata}

Hasil perhitungan skoring mengenai sistem tata ruang diperoleh skor penilaian 152, ini berarti berdasarkan pengklasifikasian OWA Pantai Lubang Buaya memiliki sistem tata ruang yang kurang baik menurut persepsi pengunjung, karena berdasarkan pengamatan di lapangan bahwa kondisi sistem tata ruang memerlukan pembenahan yang lebih optimal, dimana perlu dilakukan penataan yang lebih baik terhadap tata letak fasilitas yang ada seperti tempat bersantai, toilet, parkir serta fasilitas lainnya sehingga intensitas kunjungan dapat semakin meningkat. 
Nilai Ekonomi Objek Wisata Alam Pantai Lubang Buaya Di Negeri Morella Kabupaten Maluku Tengah

Pratiwi Herlina W., Iskar \& Thomas M. Silaya

Tabel 5. Rekapitulasi Pendapat Responden Mengenai Sistem Tata Ruang

\begin{tabular}{lccc}
\hline \multicolumn{1}{c}{ Sistem Tata Ruang } & Skala Penilaian & Jumlah (Orang) & Jumlah Skor Penilaian \\
\hline Sangat Baik & 3 & 1 & 3 \\
Baik & 2 & 50 & 100 \\
Kurang Baik & 1 & 49 & 49 \\
\hline Total & & 100 & 152 \\
\hline
\end{tabular}

Sumber: Data Primer Diolah, 2017

\section{Fasilitas Wisata}

Hasil perhitungan skoring mengenai fasilitas wisata diperoleh skor penilaian 122, ini berarti berdasarkan pengklasifikasian OWA Pantai Lubang Buaya memilik fasilitas yang kurang lengkap, karena mengingat tidak adanya fasilitas untuk rambu-rambu peringatan pada lokasi tersebut dimana lokasi objek wisata ini memiliki keindahan alam bawah laut yang indah, dan tidak ada tim yang khusus menangani masalah keselamatan pengunjung seperti halnya penjaga pantai, serta fasilitas pendukung lainnya yang harus pengelola sediakan.

Tabel 6. Rekapitulasi Pendapat Responden Mengenai Fasilitas Wisata

\begin{tabular}{lccc}
\hline \multicolumn{1}{c}{ Fasilitas Wisata } & Skala Penilaian & Jumlah (Orang) & Jumlah Skor Penilaian \\
\hline Sangat Lengkap & 3 & 0 & 3 \\
Lengkap & 2 & 19 & 38 \\
Kurang Lengkap & 1 & 81 & 81 \\
\hline Total & & 100 & 122 \\
\hline Sumber: Data Primer Diolah, 2017 & & &
\end{tabular}

\section{Daya Tarik Wisata OWA Pantai Lubang Buaya}

Daya tarik wisata OWA Pantai Lubang Buaya memiliki hasil penilaian yang tertinggi pada unsur keindahan, secara rinci dapat dilihat pada Tabel 7.

Tabel 7. Kriteria Penilaian Wisata Alam Berbentuk Pantai

\begin{tabular}{clcccc}
\hline No & \multicolumn{1}{c}{ Unsur } & $\begin{array}{c}\text { Kriteria Penilaian } \\
\text { berdasarkan PHKA }\end{array}$ & $\begin{array}{c}\text { Nilai Hasil } \\
\text { Penelitian }\end{array}$ & Bobot & $\begin{array}{c}\text { Nilaix } \\
\text { Bobot }\end{array}$ \\
\hline 1 & Keindahan & 35 & 35 & 6 & 210 \\
2 & $\begin{array}{l}\text { Keselamatan/keamanan } \\
\text { pantai }\end{array}$ & 30 & 20 & 6 & 120 \\
3 & Jenis dan warna pasir & 30 & 10 & 6 & 60 \\
4 & Variasi kegiatan & 30 & 25 & 6 & 150 \\
5 & Kebersihan / kenyamanan & 30 & 20 & 6 & 120 \\
6 & Lebar pantai & 30 & 10 & 6 & 60 \\
7 & Kenyamanan & 30 & 30 & 6 & 180 \\
\hline
\end{tabular}

Sumber : Data Primer Diolah, 2017

Berdasarkan Tabel 7, kriteria penilaian wisata alam berbentuk pantai pada OWA Pantai Lubang Buaya, maka setiap unsur dapat diuraikan sebagai berikut ini:

a) Unsur Keindahan, Jenis dan Warna Pasir

OWA Pantai Lubang Buaya memiliki keindahan pesona pantai dan pesona daya tarik pulau/gunung di laut, yang dapat dinikmati oleh pengunjung dalam melakukan kunjungan 
Nilai Ekonomi Objek Wisata Alam Pantai Lubang Buaya Di Negeri Morella Kabupaten Maluku Tengah (Pratiwi Herlina W., Iskar \& Thomas M. Silaya)

ekowisata di OWA Pantai Lubang Buaya. Pesona daya tarik keserasian pandangan pantai dan sekitarnya, baik laut maupun daratan dengan pepohonan yang hijau sangat memanjakan mata. Jenis pasir pada OWA Pantai Lubang Buaya sedikit berpasir dan batuan karang yang ada di tempat ini memiliki keunikan tersendiri seperti batuan yang berbentuk seperti lubang, batuan yang berlubang inilah yang menyebabkan OWA ini dinamakan Pantai Lubang Buaya serta ada batuan - batuan yang mirip seperti buaya.

\section{b) Unsur Keselamatan / Keamanan Pantai}

OWA Pantai Lubang Buaya tidak memiliki arus balik yang berbahaya, bebas dari racun, tidak ada kepercayaan yang mengganggu, tidak ada gangguan manusia karena Objek Wisata ini jauh dari pemukiman hanya saja pengunjung harus berhati - hati saat melakukan aktifitas dilaut dikarenakan OWA Pantai Lubang Buaya memiliki tubir dan juga lebar pantai dihitung dari surut terendah $<50 \mathrm{~m}$. Sehingga pengunjung yang datang dan ingin melakukan aktifitas seperti berenang harus tetap waspada, terlebih mereka yang membawa anak - anak harus ada pengawasan dari orang tua atau orang dewasa.

c) Variasi Kegiatan

Aktivitas pengunjung alam ini dapat diharapkan melindungi alam, menambah keindahan alam agar keindahan dan rekreasi dapat dicapai kepuasan yang tinggi. Pengembangan wisata berbasis alam seluruh aktivitas wisata yang dilakukan pengunjung harus diarahkan dalam rangka meningkatkan kepedulian terhadap alam (Fandeli, 2002). Berdasarkan variasi kegiatan yang sesuai dengan penilaian maka ada 5 Variasi kegiatan yang didapat yaitu berjemur, berenang, menikmati pemandangan, dan bersampan. Namun tidak menutup kemungkinan pengunjung dapat melakukan lebih dari aktivitas tersebut seperti misalnya saja memancing, diving, dan photography.

\section{d) Kebersihan dan Kenyamanan}

OWA Pantai Lubang Buaya merupakan salah satu objek wisata alam yang memiliki potensi bagi pengunjung yang ingin memanjakan mata dengan pesona pantai yang masih alami, air laut yang jernih yang divariasi oleh bebatuan alami, dan terumbu karang yang tidak kalah indahnya. Hal tersebut dikarenakan OWA Pantai Lubang Buaya tidak memiliki pengaruh dari pemukiman penduduk karena kesadaran akan kebersihan yang lebih dari masyarakat lokal sendiri, sehingga tidak ada sampah yang tercemar dan bebas dari bau apapun, tidak ada pengaruh dari sungai, tidak ada pengaruh pelelangan ikan/pabrik/pasar yang mengganggu ketenangan (bebas dari kebisisngan), tidak ada sumber pencemaran lain (vandal, gangguan manusia, tidak banyak gangguan binatang), serta tidak ada pengaruh musim. Sehingga dari beberapa sub-unsur yang dimiliki tersebut, maka kebersihan dan kenyamanan dari OWA Pantai Lubang Buaya harus tetap terjaga. 



\section{Nilai Ekonomi Objek Wisata Alam Pantai Lubang Buaya}

Menurut Jala (2015), salah satu teknik valuasi ekonomi yang dapat digunakan untuk menilai jasa lingkungan berupa keindahan alam yang dimanfaatkan sebagai objek wisata dapat dilakukan dengan metode biaya perjalanan atau Travel Cost Method (TCM). Premis dasar dari metode biaya perjalanan menyatakan bahwa waktu dan biaya perjalanan yang dikeluarkan oleh individu untuk mengunjungi suatu lokasi mewakili harga untuk mengakses tempat tersebut (Jala, 2015) dan juga biaya perjalanan merupakan salah satu faktor yang mempengaruhi intensitas kunjungan, kenaikan biaya perjalanan mengakibatkan pengunjung mengurangi kunjunganya ke objek wisata.

Berdasarkan data penelitian terlihat bahwa besarnya biaya perjalanan rata-rata yang harus dikeluarkan oleh pengunjung adalah sebesar Rp. 69.220/orang/kunjungan. Salah satu indikator yang dapat mempengaruhi biaya perjalan adalah letak suatu objek wisata dari tempat tinggal pengunjung, biaya konsumsi dan biaya lainnya yang akan dikeluarkan setiap pengunjung menuju suatu objek wisata. Dengan demikian kondisi ini menunjukkan bahwa kegiatan wisata adalah salah satu kegiatan yang bersifat ekonomis. Dalam ilmu ekonomi menyatakan bahwa konsumen akan meningkatkan jumlah permintaan terhadap suatu komoditi apabila harga komoditi tersebut berkurang. Kondisi ini juga berkolerasi terhadap permintaan wisata dimana apabila semakin tinggi biaya perjalanan yang dikeluarakan oleh pengunjung menuju suatu lokasi objek wisata maka, pengunjung memiliki kecenderungan untuk memilih tempat wisata alternatif dengan biaya yang lebih rendah.

Berdasarkan rekapitulasi data biaya yang dikeluarkan responden dalam melakukan kegiatan wisata total biaya perjalanan, maka diperoleh nilai ekonomi total Objek Wisata Alam Pantai Lubang Buaya adalah sebesar Rp. 83.064.000/tahun. Dalam penelitian ini juga ditanyakan mengenai kesediaan pengunjung untuk membayar tiket masuk ke lokasi Objek Wisata Alam Pantai Lubang Buaya. Kesediaan membayar erat kaitanya dengan pendapatan seseorang, seseorang yang mempunyai pendapatan tinggi mungkin memiliki kecenderungan kesediaan membayar yang lebih tinggi dibandingkan dengan orang yang berpendapatan lebih rendah.

Menurut hasil wawancara dari kuisioner di lapangan, sebagian besar pengunjung bersedia untuk mengeluarkan biaya tambahan maksimal Rp. 5.000 jika berbagai fasilitas rekreasi ditambah dan ditingkatkan kualitasnya. Adapun bentuk fasilitas yang menurut responden perlu ditingkatkan atau diperbaiki kualitasnya antara lain tempat makan, jalan yang ada di lokasi wisata, tempat parkir kendaraan, dan tempat istirahat (Resort). Sedangkan fasilitas yang perlu ditambahkan adalah papan informasi, fasilitas pendukung (P3K), tempat sampah, 

Nilai Ekonomi Objek Wisata Alam Pantai Lubang Buaya Di Negeri Morella Kabupaten Maluku Tengah (Pratiwi Herlina W., Iskar \& Thomas M. Silaya)Pratiwi Herlina W., Iskar \& Thomas M. Silaya

dan penjual souvenir. Pengelolaan yang baik dari Objek Wisata Alam Pantai Lubang Buaya sangat diperlukan untuk meningkatkan jumlah pengunjung di kawasan ini.

\section{KESIMPULAN}

Hasil analisis dengan biaya perjalanan (Travel Cost) diperoleh biaya perjalanan 69.220/orang/kunjungan dan nilai ekonomi OWA Pantai Lubang Buaya adalah sebesar Rp. 83.064.000 / tahun.

OWA Pantai Lubang Buaya dalam persepsi pengunjung merupakan tempat rekreasi yang aman, memiliki keindahan alam yang indah, aksesibilitas mudah, hanya saja tata ruang kurang baik dan fasilitas wisata yang kurang lengkap. Sehingga perlu adanya penambahan fasilitas dan pengelolaan yang lebih baik lagi. Hasil penelitian daya tarik objek wisata pantai diperoleh hanya unsur keindahan dan kenyamanan memiliki semua aspek penilaian dari ketujuh unsur kriteria penilaian.

\section{DAFTAR PUSTAKA}

Direktur Jenderal Pengembangan Daya Tarik Wisata. 2013. Modul Bimbingan Teknis. Jakarta

Fandeli, C. 2002. Perencanaan Kepariwisataan Alam. Yogyakarta : Fakultas Kehutanan Universitas Gadjah Mada.

Fauzi, A. 2006. Ekonomi Sumber Daya Alam dan Lingkungan teori Dan Aplikasi. Gramedia Pustaka Utama

Jala \& Nandagiri, L. 2015. Evaluation of Economic Value of Pilikula Lake Using Travel Cost and Contingent Valuation Methods. Aquatic Procedia, 4, 1315-1321.

Susilowati, 2009. Valuasi Ekonomi Manfaat Rekreasi Taman Hutan Raya IR. H. Djuanda Dengan Menggunakan Pendekatan Travel Cost Method. Departemen Ekonomi Sumberdaya dan Lingkugan Fakultas Ekonomi dan Manajemen Institut Pertanian Bogor.

Suwantoro, G. 2002. Dasar-dasar Pariwisata. Penerbit Andi. Yogyakarta.

Sulistiono, N. 2007. Pengantar Ekoturisme. Dalam Afandi O. (Ed.) Buku Panduan Praktik Pengenalan dan Pengelolaan Hutan. Departemen Fakultas Pertanian, Sumatra Utara, Medan.

Sugiyono. 2014. Memahami Penelitian Kualitatif. Penerbit CV. Alfabeta, Bandung 